\title{
Assessment of Banana and Jute Fiber Composites Made up of GP- Resins as a Casting Agent
}

\author{
Maruthi Prashanth ${ }^{1}$, Arvind Kumar ${ }^{2}$, Shridhar ${ }^{3}$, Ramesh. $\mathbf{S}^{4}$, Sudheersajjan ${ }^{5}$ \\ Assistant Professor, Mechanical Engineering Department, BIT, Mangalore, Karnataka, India ${ }^{1,2,3,4,5}$
}

\begin{abstract}
Recent years there has been a fast increase in the development of composite materials, particularly in the automobile and aerospace industries, due to their high strength to weight ratio, high wear resistance, low density and low coefficient of thermal expansion. The advancements in the field of application make the study of their desirable properties like bending, compression and tensile got utmost importance. This paper attempts to assess the desirable properties of the composite material which has been made up with Banana fibers, Jute Fiber and, Resin Epoxy (LY-556) and hardener (HY917).In this work we have compared 3 different composite materials, that is material is the same but the size of the material are varied across different materials.. The results obtained shows that the composite possesses good tensile and bending strength comparatively.
\end{abstract}

Key Words: Banana fibers, Jute Fiber, Resin Epoxy (LY-556) and Hardener (HY-917).

\section{INTRODUCTION}

Composites are materials that comprise strong load carrying material (known as reinforcement) imbedded in weaker materials (known as matrix). Reinforcement provides strength and rigidity, helping to support structural load. The matrix or binder (organic or inorganic) maintains the position, orientation of the reinforcement and transfers the external load to the reinforcement. Jute has been used since ancient times in Africa and Asia to provide cordage and weaving fiber from the stem and food from the leaves cylinder The advantage of composite materials over conventional materials stem large from their higher specific strength, stiffness and fatigue characteristics, which enables structural design to be more versatile. By definition, composite materials consist of two or more constituents with physically separable phases. However, only when the composite phase materials have notably different physical properties it is recognized as being a composite material.

Composites are materials that comprise strong load carrying material (known as reinforcement) imbedded in weaker material (known as matrix).Reinforcement provides strength and rigidity, helping to support structural load. The matrix or binder (organic or inorganic) maintains the position and orientation of the reinforcement. Significantly, constituents of the composites retain their individual, physical and chemical properties; yet together they produce a combination of qualities which individual constituents would be incapable of producing alone. Particulate Composites consist of a matrix reinforced by a dispersed phase in form of particles.

\section{DETAILS OF EXPERIMENT}

\subsection{Preparation of Banana fibers}

For preparation of the banana fibers specimens the fibers are extracted through hand extraction machine composed of either serrated or non-serrated knives. The peel is clamped between the wood plank and knife and hand-pulled through, removing the non-fibrous material. The extracted fibers are sun-dried which whitens the fiber.

Once dried, the fibers are ready for knotting. A bunch of fibers are mounted or clamped on a stick to facilitate segregation. Each fiber is separated according to fiber sizes and grouped accordingly

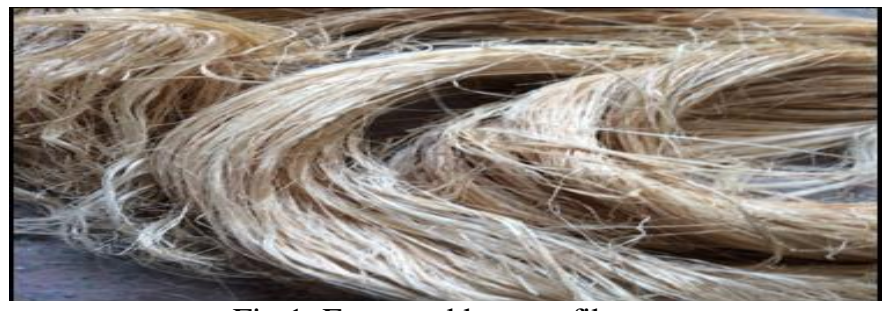

Fig.1. Extracted banana fibers 


\section{International Advanced Research Journal in Science, Engineering and Technology ISO 3297:2007 Certified \\ Vol. 4, Issue 5, May 2017}

\subsection{Preparation of jute fibers}

It is a baste stem fiber obtained from the stems of various dicotyledonous plants. Most of the jute is harvested when about $50 \%$ of the plants are in pod because it is during this stage of growth that high quality jute fiber bundles can be obtained. The fiber bundles are separated from the woody stem by the retting process.

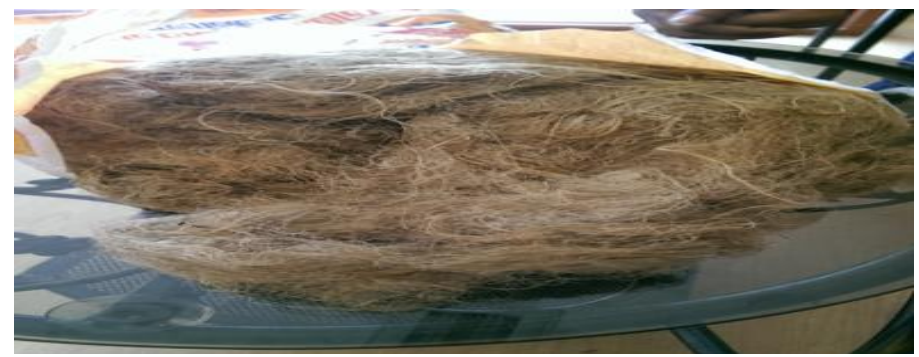

Fig.2. Extracted jute fibers

\subsection{Fabrication process}

The fabrications of composite slab are carried out by conventional hand layup technique. The dimensions of length and breadth is of $300 * 300 \mathrm{~mm}$ was used to prepare the specimen. The composite specimen consists of totally 3 Layers of Banana Fiber for the preparation of one sample. A measured amount of epoxy is taken and mixed with the hardener in the ratio of 10:1. The layers of fibers were fabricated by adding the required amount of epoxy resin. The Banana fiber is mounted on the table and then epoxy resin applies and next layer is jute fiber. Before the resin gets dried, the second layer of natural fiber is mounted over the Banana fiber. The process is repeated till 3 layers of fiber. The epoxy resin applied is distributed to the entire surface by means of a roller. The air gaps formed between the layers during the processing were gently squeezed out. The processed wet composite were then pressed hard and the excess resin is removed and dried. Finally these specimens were hydraulic pressed to force the air present in between the fibers and resin, and then kept for several hours to get the perfect samples. After the composite material dried completely, the composite material was taken out from the hydraulic press and rough edges were neatly cut and removed as per the required ASTM standards.

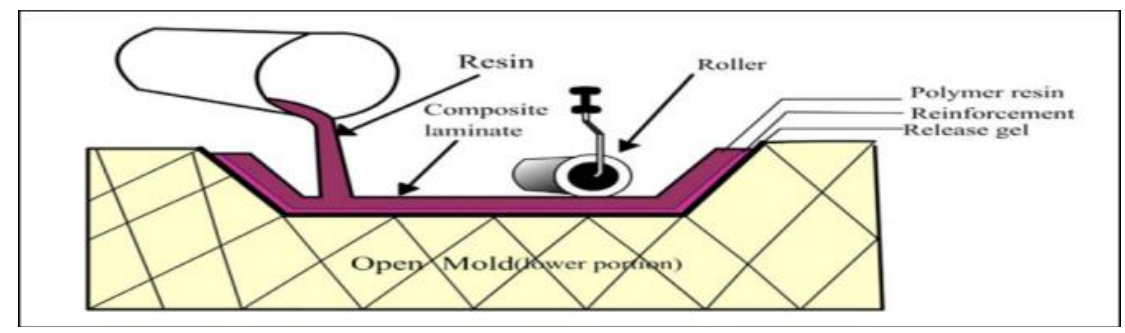

Fig.3. Hand layup process

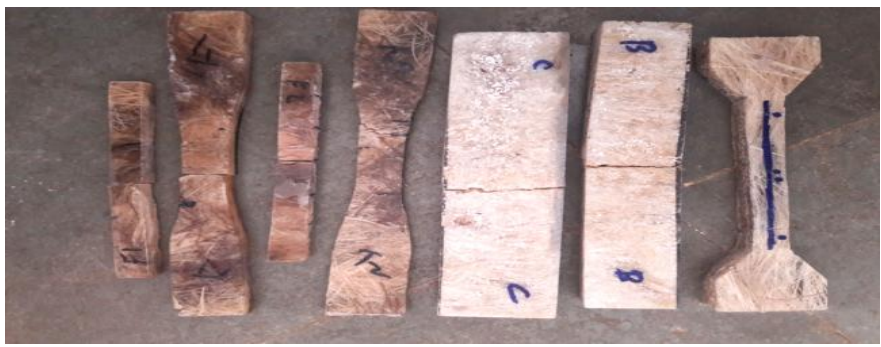

Fig.4. Standard Specimen

\section{REQUIRED TESTS}

\subsection{TENSILE TEST}

As per ASTM standards the test is performed for different measurements. A tensile load is applied to the specimen until it fractures. During the test, the load required to make a certain elongation on the material is recorded. A load-elongation curve is plotted by an $\mathrm{x}-\mathrm{y}$ recorder, so that the tensile behavior of the material can be obtained. 


\section{IARJSET \\ Vol. 4, Issue 5, May 2017}

\subsection{Compressive Test}

Compressive strength has been done as per ASTM standards its often measured on a universal testing machine; these range from very small table-top systems to ones with over $53 \mathrm{MN}$ capacity. Measurements of compressive strength are affected by the specific test method and conditions of measurement. Compressive strengths are usually reported in relationship to a specific technical standard.

\subsection{Bending Test}

Bending tests are carried out as per ASTM standards. It's designed so that the outer surface of the specimen is stretched to a ductility level that approximates the minimum percent elongation required in a tensile test. When defects exist in materials strained to these limits, the material tears locally. When tearing exceeds a specific limit, the specimen fails.

\section{RESULTS AND DISCUSSION}

\subsection{Tensile test of fiber sample 1}

$\begin{array}{ll}\text { Sample } & : \text { Fiber sample } 20 \mathrm{~mm} \\ \text { Specimen width } & : 19.5 \mathrm{~mm} \\ \text { Specimen thickness } & : 8.2 \mathrm{~mm} \\ \text { Yield stress } & : 2.56 \mathrm{~N} / \mathrm{mm} 2 \\ \text { Tensile stress } & : 3.63 \mathrm{~N} / \mathrm{mm} 2 \\ \% \text { elongation } & : 1.75 \% \\ \text { Test standard } & : \text { ASTM D638 }\end{array}$

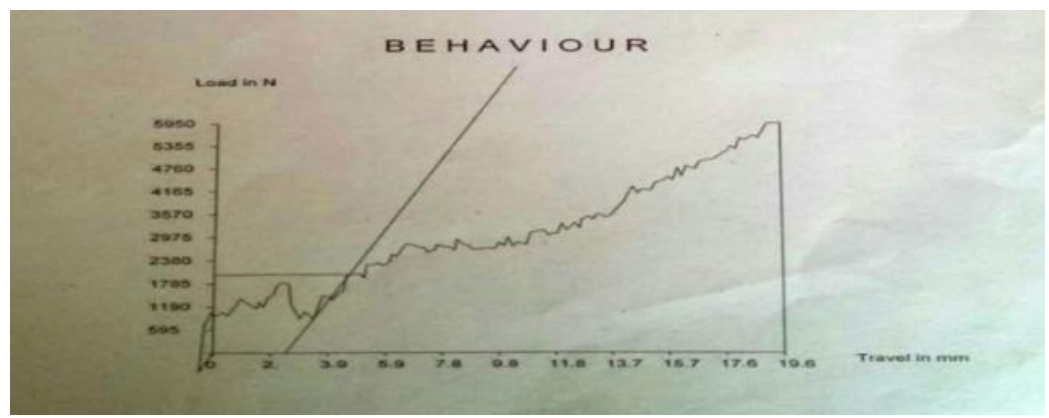

Fig.5. Stress vs. strain graph

\subsection{Tensile test of fiber sample 2}

Sample

Specimen width

Specimen thickness

Yield stress

Tensile stress

$\%$ elongation

Test standard
: Fiber sample $30 \mathrm{~mm}$

: $19.3 \mathrm{~mm}$

$: 13.8 \mathrm{~mm}$

: $7.58 \mathrm{~N} / \mathrm{mm} 2$

: $22.34 \mathrm{~N} / \mathrm{mm} 2$

$: 1.75 \%$

: ASTM D638

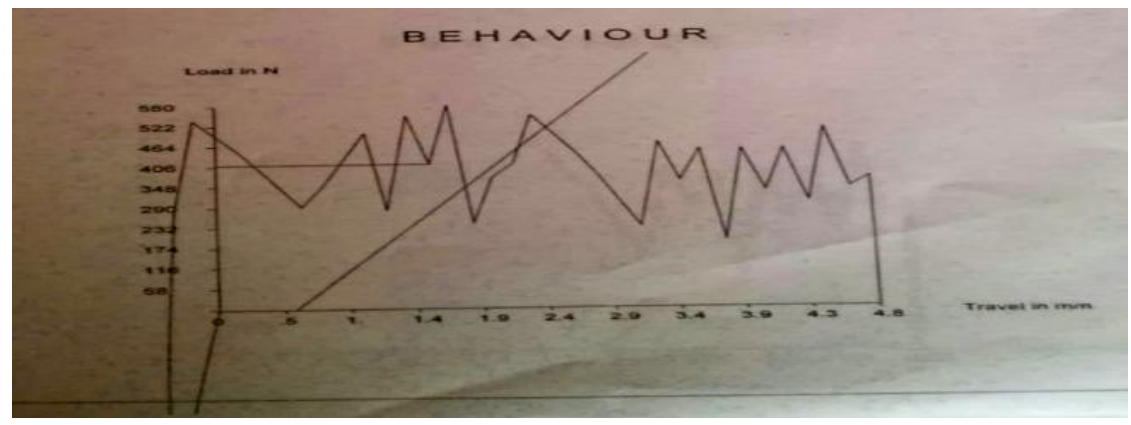

Fig.6. Stress vs. strain graph 
4.3 Tensile test of fiber sample 3

\begin{tabular}{|c|c|c|}
\hline Specimen & Load $(\mathrm{N})$ & Flexural Stress $\left(\mathrm{N} / \mathrm{mm}^{2}\right)$ \\
\hline Specimen & Load $(\mathrm{N})$ & Flexural Stress $\left(\mathrm{N} / \mathrm{mm}^{2}\right)$ \\
\hline Material 1 & 680 & 4.476 \\
\hline Material 2 & 870 & 5.835 \\
\hline
\end{tabular}

Sample

Specimen width

Specimen thickness

Yield stress

Tensile stress

$\%$ elongation

Test standard
: Fiber sample $240 \mathrm{~mm}$

$: 13.75 \mathrm{~mm}$

: $18.8 \mathrm{~mm}$

: $3.971 \mathrm{~N} / \mathrm{mm} 2$

: $5.648 \mathrm{~N} / \mathrm{mm} 2$

$: 1.58 \%$

: ASTM

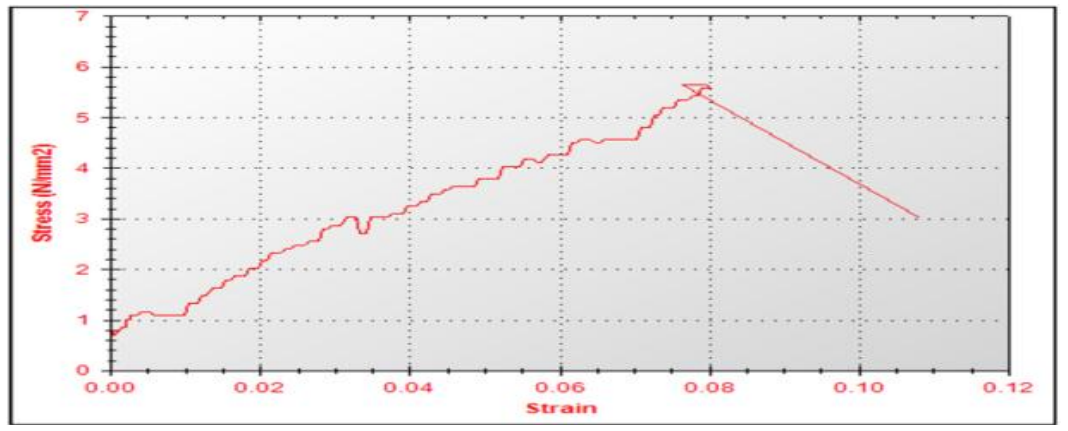

Fig.7. Stress vs. strain graph

\subsection{Bending test of fiber sample 1}

Sample

: fiber sample $20 \mathrm{~mm}$

Specimen width

: $14.25 \mathrm{~mm}$

Specimen thickness

Load

$: 12.5 \mathrm{~mm}$

Flexural stress

$: 870 \mathrm{~N}$

Test standard

$: 4.76 \mathrm{~N} / \mathrm{mm} 2$

: ASTM D790.

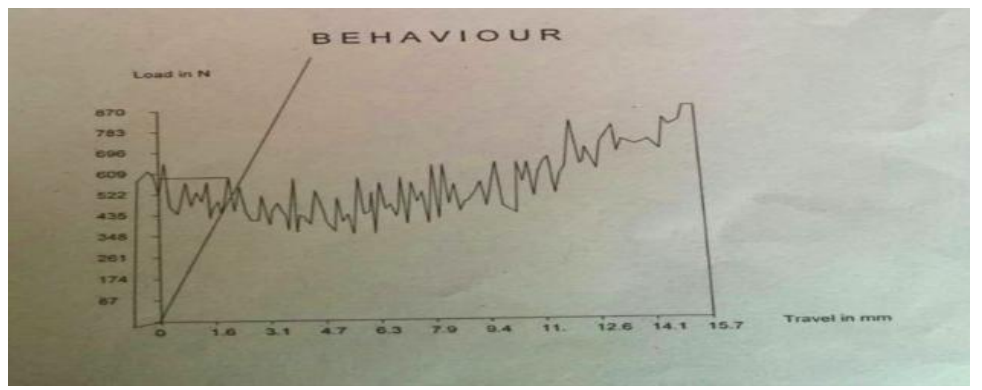

Fig.8. Stress vs. strain graph

\subsection{Bending test of fiber sample 2}

Sample

Specimen width

Specimen thickness

Load

Flexural stress

Test standard
: fiber sample $30 \mathrm{~mm}$

: $14.2 \mathrm{~mm}$

: $12.6 \mathrm{~mm}$

$: 870 \mathrm{~N}$

: $5.35 \mathrm{~N} / \mathrm{mm}^{2}$

: ASTM D790 


\section{International Advanced Research Journal in Science, Engineering and Technology}

ISO 3297:2007 Certified

Vol. 4, Issue 5, May 2017

5.3 Bending test of fiber sample 3

Sample : Fiber sample $240 \mathrm{~mm}$

Specimen width

: $45.55 \mathrm{~mm}$

Specimen thickness

$: 18.54 \mathrm{~mm}$

Bend strength: $5.67 \mathrm{~N} / \mathrm{mm} 2$

Test standard: ASTM A370:2015

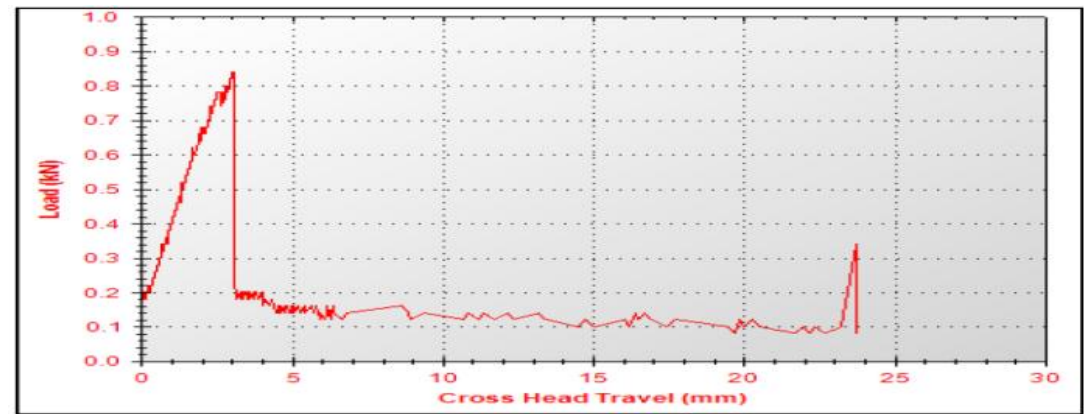

Fig.9. Stress vs. strain graph

6.3 Compressive Test for fiber sample $240 \mathrm{~mm}$

Sample

: fiber sample $240 \mathrm{~mm}$

Width

$: 35.9 \mathrm{~mm}$

Length

: $19.06 \mathrm{~mm}$

Compressive strength

: $4.647 \mathrm{~N} / \mathrm{mm} 2$

Test standard

: ASTMA370:2015

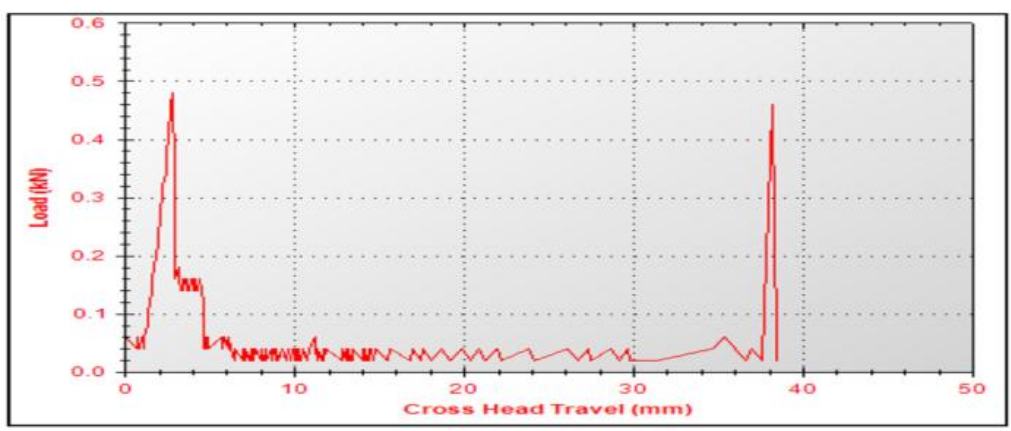

Fig.10. Stress vs. strain graph

\subsection{Tensile results comparison}

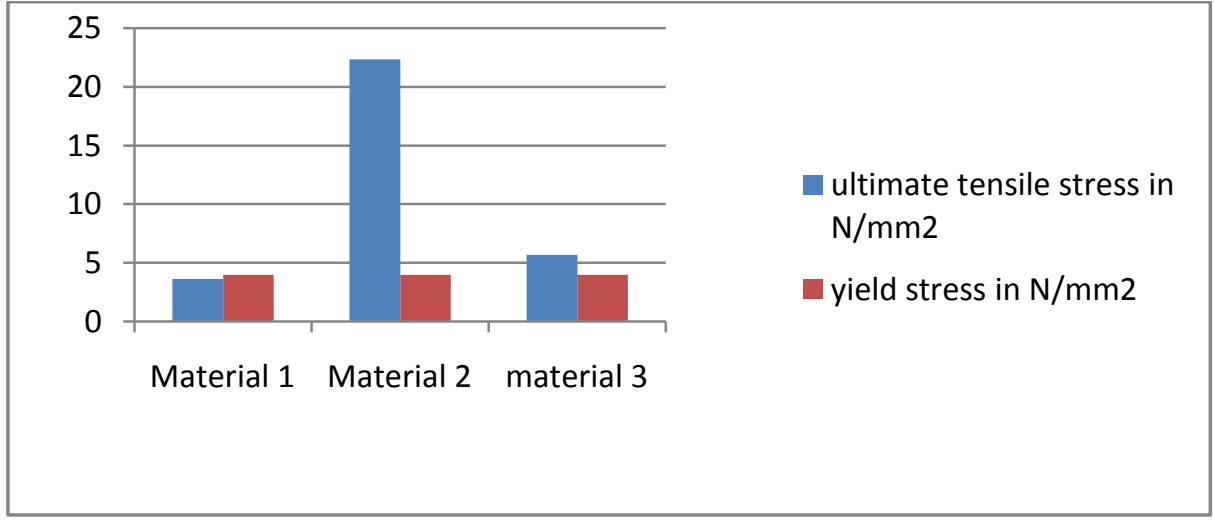

Fig.11. Tensile stress comparison graph 


\section{International Advanced Research Journal in Science, Engineering and Technology ISO 3297:2007 Certified \\ Vol. 4, Issue 5, May 2017}

\subsection{Bending results comparison}

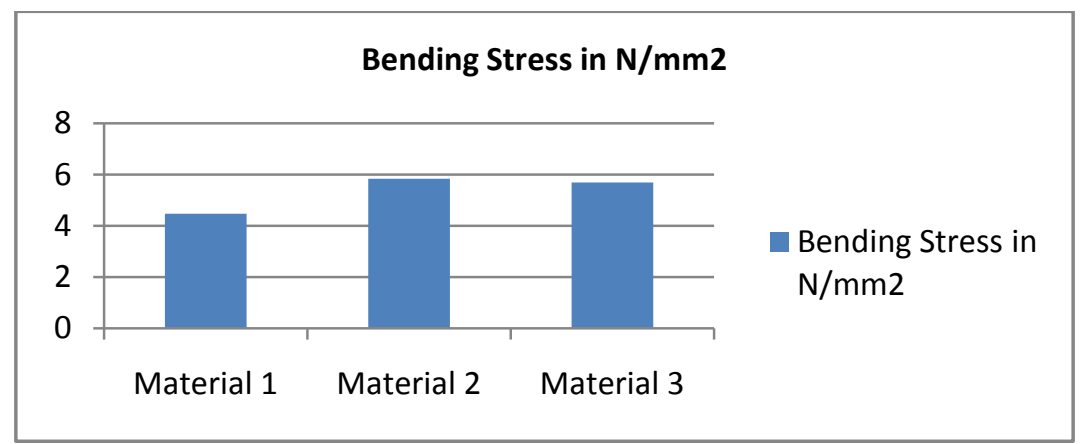

Fig.12. Bending stress comparison graph

\subsection{Overall results comparison}

\begin{tabular}{|c|c|c|}
\hline Material type & Tensile strength & Bending strength \\
\hline Full length fibred material & $5.648 \mathrm{~N} / \mathrm{mm}^{2}$ & $5.648 \mathrm{~N} / \mathrm{mm}^{2}$ \\
\hline 20mm length fibered material & $3.63 \mathrm{~N} / \mathrm{mm}^{2}$ & $4.76 \mathrm{~N} / \mathrm{mm}^{2}$ \\
\hline 30mm length fibered material & $22.34 \mathrm{~N} / \mathrm{mm}^{2}$ & $5.35 \mathrm{~N} / \mathrm{mm}^{2}$ \\
\hline
\end{tabular}

\section{CONCLUSIONS}

The experiment leads to the conclusion such that natural fibers got desirable mechanical properties which are essential for the manufacturing of fiber reinforced composites. These are comparatively cheaper and produce good results. Hence the utilization and application of the cheaper goods in high performance appliance is possible with the help of this composite technology.

\section{REFERENCES}

1. Andrzej K. BledzkiMechanical properties of PLA composites with man-made cellulose and abaca fibresInstitutfürWerkstofftechnik, Kunststoff- und Recyclingtechnik, University of Kassel, Mönchebergstr. 3, 34109 Kassel, Germany.

2. Hitoshi TakagiEffect of physicochemical structure of natural fiber on transverse thermalconductivity of unidirectional abaca/bamboo fiber composites Institute of Technology and Science, The University of Tokushima, 2-1 Minamijosanjima-cho, Tokushima 770-8506, Japan.

3. NaozumiTeramotoBiodegradation of aliphatic polyester compositesreinforced by abaca fiber Department of Life and Environmental Sciences, Faculty of Engineering, Chiba Instituteof Technology Received 20 January 2004.

4. Laly A. PothanThe role of fibre/matrix interactions on the dynamicmechanical properties of chemically modifiedbanana fibre/polyester composites Department of Chemistry, Bishop Moore College, Mavelikara, Kerala, IndiaReceived 4 September 2005; accepted 4 September 2005.

5. Magda G. El-MeligyStudy mechanical, swelling and dielectric properties of prehydrolysed bananafiber - Waste polyurethane foam composites Cellulose and Paper Department, National Research Center, Dokki, Cairo, Egypt. 